\title{
Experimental Research on Flexural Performance of High-strength Simply Supported Reinforced Concrete Beam
}

 \\ ${ }^{1}$ State Key Laboratory of Disaster Prevention and Mitigation of Explosive and Impact, PLA University \\ of Science and Technology, Nanjing210007, Jiangsu, China; \\ ${ }^{2}$ Beijing Canbao Architectural Design Institute, Beijing100850, China; \\ ${ }^{3}$ No.5 Air Defense Engineering Department of PLA Air force, Nanjing211100, Jiangsu, China

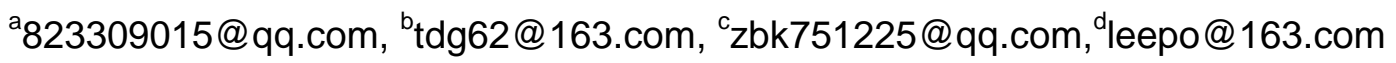

\begin{abstract}
Keywords: high-strength steel; concrete simply supported beam; flexural performance;
Abstract: In order to study the flexural performance of high strength reinforced concrete beam, through the loading test of six groups of specimens, investigate its force deformation characteristic. Test shows that the high-strength steel has very notable significance to improve the bearing capacity of the beam. The yield deflection and breakage load of the beam are also gradually increased with the continuous enhancement of the steel strength. Calculate the periodical value of load and deflection of the concrete beams according to the code and simplified $M-N-\phi$ calculation method. After the comparative analysis of the test results, amend the calculation formula for the deflection of yield and breakage of high strength reinforced concrete beam. And the calculation results coming from the amended formula are in good agreement with the experimental results.
\end{abstract}

\section{Introduction}

High strength steel with high strength, good ductility, low carbon content, can play a role to improve the safety performance of buildings. Studies have shown that when use of high strength reinforced concrete tunnel lining, there is a substantial increase in its seismic performance than ordinary steel [1]; The ratio of high rate reinforcement steel ratio of reinforced concrete reactor pressure vessels up to $16 \%$ to $24 \%$ [2], there is no doubt the use of high-strength steel can make the design of these kinds of reinforcement structures become more flexible. In addition, high-strength steel is more energy efficient, and more environmentally friendly.

Currently high-strength steel has been widely used in many developed countries, China has increased the relevant provisions of HRB500 in the "Code for design of concrete structures " (GB50010-2010) [3], and many Chinese experts have also done a lot of research about high strength steel. ZhouJianmin studied the distribution of crack and proposed a simplified formula on the basis of the short term deformation of high strength reinforced concrete beam [4 5]; HuangWei proposed a design formula of its resisting shear bearing capacity under concentrated load [6]; GeWenjie studied the flexural performance of HRBF RC beams [7]. But they are mainly concentrated in the study of 500Mpa grade steel, for HTB600 and HTB700 rebar were rarely studied. In order to promote the use of high-strength steel and provide experimental basis and technical support in engineering application, all aspects of its performance should be studied as soon as possible.

\section{Experimental Research}

The main test is a high strength reinforced concrete beam bending test, the size of the beam is taken as $1800 \mathrm{~mm} \times 300 \mathrm{~mm} \times 150 \mathrm{~mm}$, the span of $1500 \mathrm{~mm}$. The maximum load of the test machine is $4000 \mathrm{kN}$, meet the test requirements.

Specimen Design. Tests include different grades of steel, and different reinforcement ratio of concrete beams with different intensity levels. There are two reinforcement ratio of $0.6 \%$ and $1.0 \%$, three kinds of rebar of HRB400,HTB600, and HTB700, two kinds of concrete of C40 and C60. Specimens number of each group are shown in Table 1. 
Tab.1 Experimental working conditions

\begin{tabular}{cccccc}
\hline $\begin{array}{c}\text { Specimens } \\
\text { number }\end{array}$ & $\begin{array}{c}\text { Reinforced } \\
\text { species }\end{array}$ & $\begin{array}{c}\text { Types of } \\
\text { concrete }\end{array}$ & $f_{\text {cu }}^{0}$ & $\begin{array}{c}\text { Reinforcement } \\
\text { ratio }\end{array}$ & Quantity \\
\hline 4C406 & HRB400 & C40 & $48.2 \mathrm{Mpa}$ & $0.56 \%$ & 3 \\
6C406 & HTB600 & C40 & $48.2 \mathrm{Mpa}$ & $0.56 \%$ & 3 \\
7C406 & HTB700 & C40 & $44.1 \mathrm{Mpa}$ & $0.56 \%$ & 3 \\
7C410 & HTB700 & C40 & $44.1 \mathrm{Mpa}$ & $1.00 \%$ & 3 \\
7C606 & HTB700 & C60 & $67.0 \mathrm{Mpa}$ & $0.56 \%$ & 3 \\
7C610 & HTB700 & C60 & $67.0 \mathrm{Mpa}$ & $1.00 \%$ & 3 \\
\hline
\end{tabular}

Reinforced Concrete specimens are shown in Figure 1. Using two tensile reinforcement and two structural reinforcement, pure bending segment of the middle compression area is not reinforced. The stirrups using $6 \mathrm{~mm}$ diameter HRB400 Reinforcement, thickness of concrete cover is $25 \mathrm{~mm}$. The actual ratio of reinforcement beams are shown in Table 2. Specimen production including knitting bars, formwork, pouring and other processes, and then conserve 28 days.

Tab.2 Specimens actual reinforcement ratio

\begin{tabular}{ccccc}
\hline $\begin{array}{c}\text { Sectional } \\
\text { dimension } \\
{[\mathrm{mm}]}\end{array}$ & $\begin{array}{c}\text { Tensile } \\
\text { rebar }\end{array}$ & $\begin{array}{c}\text { ratio } \\
{[\%]}\end{array}$ & $\begin{array}{c}\text { The } \\
\text { stirrups }\end{array}$ & $\begin{array}{c}\text { Stirrup } \\
\text { ratio } \\
{[\%]}\end{array}$ \\
\hline $150 \times 300$ & $2 \varphi 12$ & 0.56 & $2 \varphi 6 @ 100$ & 0.38 \\
$150 \times 300$ & $2 \varphi 16$ & 1.00 & $2 \varphi 6 @ 60$ & 0.63 \\
\hline
\end{tabular}



Fig.1 Specimen reinforcement and load schematic

Test design. (1) Loading method. Test loads in three equal point, loading method shown in Figure 1. Adopting a classification method of continuous loading, determine loading process according to "Standard for test method of concrete structures" (GB/T50152-2012) [8]. Before reaching the specimen yield load Fs, each level of loading is not more than 0.2Fs; Before reaching the specimen cracking load, each level of loading is about $0.1 \mathrm{Fs}$; When near the calculated cracking load value for each level of loading is about $0.05 \mathrm{Fs}$. After cracking, each loading incremental value between 0.1 0.2Fs; After the yielding, control load according to the incremental deflection, for each level is about $3 \sim 4 \mathrm{~mm}$, loading duration of each stage not less than $5 \mathrm{~min}$.

(2) Measuring points distribution. Put the displacement sensor (y) on the middle position of the beam to measure span deflection; Arrange dial indicator at the support to measure the settlement at the support girder for correcting deflection measurements; fix the force sensor (F) on the allocation distribution beam for measuring the total load. Since the tester actuation head in the lower part, take the method of inverted loading test, weld the supporting steel beams in the upper part of tester, put allocation steel beam under the specimen, and loading up from the bottom.

\section{Theoretical calculation}

Cracking load. By comparing ACI 318M-05 Building code [9], GuXianglin method[10], select GuoZhenhai method [11] to calculate the cracking load ,because its smaller error. Calculations are as follows: $F c r=\frac{6 M_{c r}}{L}, M_{c r}=\gamma_{m} W_{0} f_{t}$, take $\gamma_{m}=\frac{f_{t, f}}{f_{t}}=1.55, f_{t, r}=\frac{M_{c r}}{b h^{2} / 6} \approx 1.536 f_{t}, \quad W_{0}=I_{0} /\left(h-y_{0}\right)$, $y_{0}=\frac{b h^{2}+2\left(\alpha_{E}-1\right)\left(A_{s} h_{0}+A_{s}^{\prime} a_{s}^{\prime}\right)}{2 b h+2\left(\alpha_{E}-1\right)\left(A_{s}+A_{s}^{\prime}\right)}, \quad \alpha_{E}=\frac{E_{s}}{E_{c}}$. $\gamma_{m}$-- plastic influence coefficient of sectional resistance moment; $I_{0}$-- cross-sectional moment of inertia before cracking; $f_{t, f}$-- nominal bending tensile strength; $\mathrm{w}_{0}$-- sectional resistance moment; $y_{0}$-- neutral axis height.

Cracking deflection. According to the crack deflection formula in " Code for design of concrete structures " (GB50010-2010): 


$$
f=S \frac{M l_{0}^{2}}{B_{s}}, \quad B_{s}=\frac{E_{s} A_{s} h_{0}^{2}}{1.15 \psi+0.2+\frac{6 \alpha_{E} \rho}{1+3.5 \gamma_{f}^{\prime}}} \quad, \quad \psi=1.1-0.65 \frac{f_{t k}}{\rho_{t e} \sigma_{s q}}, \quad \sigma_{s q}=\frac{M_{c r}}{\eta^{\prime} h_{0} A_{s}}, \quad \rho_{t e}=\frac{A_{s}}{A_{t e}} .
$$

$f$-- deflection; $B_{s}$--short-term section stiffness;

$S$-- deflection factor related to load form and supporting conditions, take $S=23 / 216$ [12];

$\gamma_{f}^{\prime}$-- ratio of compression flange and effective cross-sectional area of web-section;

$\sigma_{s q}{ }^{--}$longitudinal tensile reinforcement stress;

$\eta^{\prime}-$ arm coefficient of cracks at the stage normal use, take $\eta^{\prime}=0.87$;

$A_{t e}$-- cross-sectional area of effective tension concrete.

Yield load. Calculate moment according to " Code for design of concrete structures ":

$$
F_{y}=\frac{6 M_{y}}{L}, M_{y}=f_{y} A_{s} h_{0}\left(1-0.5 \rho \frac{f_{y}}{\alpha_{1} f_{c}}\right),
$$

$\rho$-- tensile reinforcement ratio; $\alpha_{1}$-- take its value according to code.

Yield deflection. Calculate the yield deflection according to the simplified $M-N-\phi$ calculation method [13]: $f=S \frac{M_{y} l_{0}^{2}}{0.85 E_{c} I_{y}}, E_{c} I_{y}=\frac{M_{y}}{\phi_{y}}, \phi_{y}=\frac{\varepsilon_{y}}{h_{0}-\eta h_{0}}, \quad \eta=\left[\left(\rho+\rho^{\prime}+\mu \frac{f_{c}}{f_{y}^{2}}\right)_{E}^{2}+2 \alpha_{E}\left(\rho^{\prime} \frac{\alpha_{s}^{\prime}}{h_{0}}+\rho+\mu \frac{f_{c}}{f_{y}}\right)\right]^{1 / 2}-\left(\rho+\rho^{\prime}+\mu \frac{f_{c}}{f_{y}}\right) \alpha_{E}$. $\phi_{y}$-- Yield curvature; $\varepsilon_{y}$-- tensile reinforcement yielding strain; $\mu$-- axial compression ratio.

Breakage load. Because there is no reinforcement in the compression zone, accordance with the simplified $M-N-\phi$ calculation method, which is $\varepsilon_{c u} \frac{x-a_{s}^{\prime}}{x} \leq \varepsilon_{y}=\frac{f_{y}^{\prime}}{E_{s}}$ :

$$
F_{u}=\frac{6 M_{u}}{L}, M_{u}=\alpha_{1} \beta_{1} b x f_{c}\left(h_{0}-0.5 \beta_{1} x\right), x=\frac{f_{y} A_{s}}{\alpha_{1} \beta_{1} b f_{c}}, \beta_{1} x b \alpha_{1} f_{c}=f_{y} A_{s}-\varepsilon_{c u} \frac{x-a_{s}^{\prime}}{x} E_{s} A_{s}^{\prime}+N ;
$$

$N$-- axial force; take $\alpha_{1}=0.77, \beta_{1}=0.85, \varepsilon_{c u}=0.004$.

Breakage deflection. $f=S \frac{M u l_{0}^{2}}{0.85 E_{c} I_{u}}, \quad E_{c} I_{u}=\frac{M_{u}}{\phi_{u}}, \quad \phi_{u}=\frac{\varepsilon_{c u}}{x}$.

\section{Data analysis.}

Comparison of experimental results and theoretical calculations. Draw the load-deflection curve of test results and theoretical calculations in the same Cartesian coordinate system with the origin software, as shown in figure $2 \sim 7$.

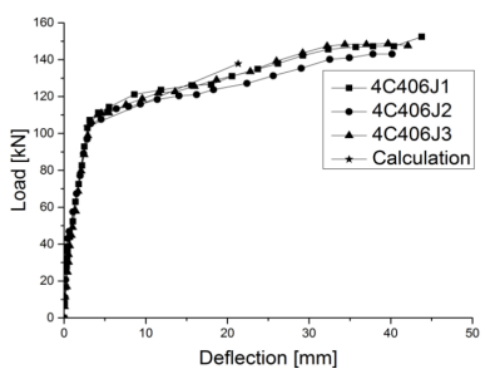

Fig.2 4C406 Load-deflection curve

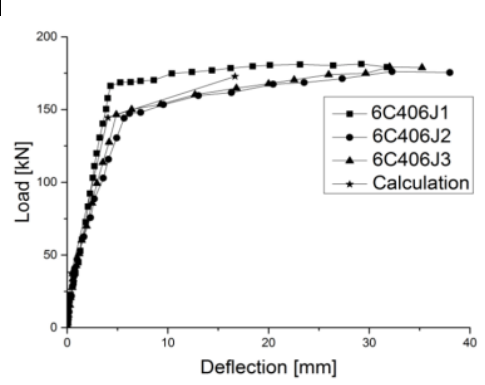

Fig.3 6C406 Load-deflection curve

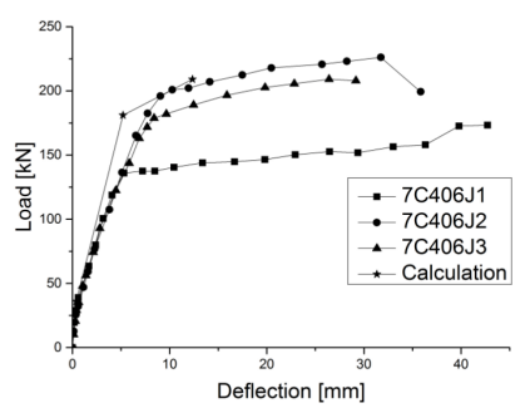

Fig.4 7C406 Load-deflection curve 


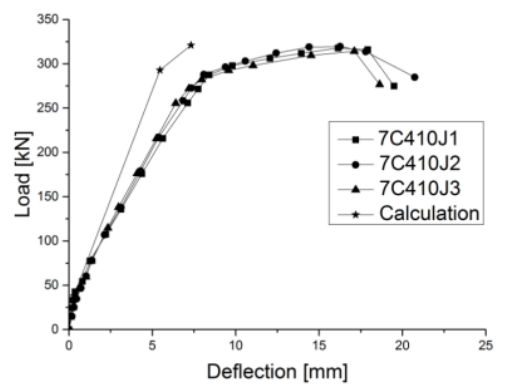

Fig.5 7C410 Load-deflection curve



Fig.6 7C606 Load-deflection curve

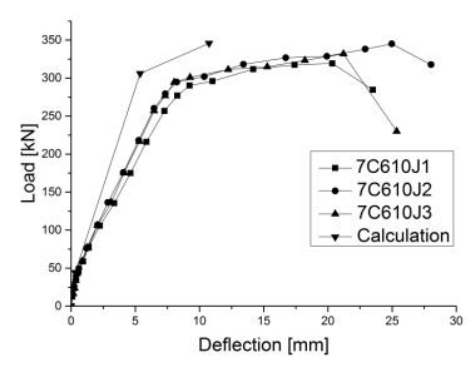

Fig.7 7C610 Load-deflection curve

Figure 2-7 and Table 3 shows that: (1) The cracking load are gradually increased with the enhancement of concrete strength, but few change because of different strength of steel; (2)The yield load and breakage load of the beam are also increased with the continuous enhancement of the ratio and strength of steel; (3) The yield deflection and breakage deflection are increased with the enhancement of the steel strength. When the reinforcement ratio increased, the yield deflection is also increased but the breakage deflection decreased.

Tab.3 Experimental, theoretical results summary

\begin{tabular}{cccccccc}
\hline $\begin{array}{c}\text { Specimens } \\
\text { number }\end{array}$ & Type & $\begin{array}{c}\text { Cracking } \\
\text { load[kN] }\end{array}$ & $\begin{array}{c}\text { Cracking } \\
\text { deflection[mm] }\end{array}$ & $\begin{array}{c}\text { Yield } \\
\text { load[kN] }\end{array}$ & $\begin{array}{c}\text { Yield } \\
\text { deflection[mm] }\end{array}$ & $\begin{array}{c}\text { Break } \\
\text { load[kN] }\end{array}$ & $\begin{array}{c}\text { Break } \\
\text { deflection[mm] }\end{array}$ \\
\hline \multirow{2}{4C406}{} & Experimental & 37 & 0.441 & 106.2 & 3.222 & 148.3 & 41.224 \\
& theoretical & 37.5 & 0.408 & 103.6 & 2.856 & 137.8 & 21.325 \\
& error & $+1.6 \%$ & $-7.5 \%$ & $-2.4 \%$ & $-12.8 \%$ & $-7.1 \%$ & $-48.3 \%$ \\
\hline \multirow{2}{*}{ C406 } & Experimental & 35.2 & 0.669 & 152.6 & 4.744 & 179.1 & 31.154 \\
& theoretical & 37.5 & 0.408 & 144.5 & 4.05 & 172.8 & 16.667 \\
& error & $+7.1 \%$ & $-39.0 \%$ & $-5.3 \%$ & $-14.6 \%$ & $-3.5 \%$ & $-46.5 \%$ \\
\hline 7 C406 & Experimental & 32.8 & 0.612 & 170.1 & 7.514 & 202.4 & 32.604 \\
& theoretical & 36 & 0.359 & 181 & 5.199 & 209.1 & 12.353 \\
& error & $+10.1 \%$ & $-35.4 \%$ & $-6.4 \%$ & $-30.8 \%$ & $+3.3 \%$ & $-62.1 \%$ \\
\hline 7 C410 & Experimental & 37.8 & 0.388 & 285.7 & 8.108 & 313.8 & 17.604 \\
& theoretical & 37.9 & 0.296 & 292.9 & 5.463 & 320.9 & 7.319 \\
& error & $+2.6 \%$ & $-23.7 \%$ & $+2.5 \%$ & $-32.6 \%$ & $-3.1 \%$ & $-58.4 \%$ \\
\hline 7 C606 & Experimental & 37 & 0.653 & 154.8 & 7.504 & 191.6 & 34.536 \\
& theoretical & 42.3 & 0.451 & 185.5 & 5.139 & 217.9 & 18.129 \\
& error & $+14.3 \%$ & $-26.3 \%$ & $+19.8 \%$ & $-31.5 \%$ & $+13.7 \%$ & $-47.5 \%$ \\
\hline 7 C610 & Experimental & 36.2 & 0.396 & 293.2 & 8.423 & 331.2 & 21.169 \\
& theoretical & 42.3 & 0.326 & 306 & 5.379 & 345.9 & 10.74 \\
& error & $+22.3 \%$ & $-17.7 \%$ & $+4.37 \%$ & $-36.1 \%$ & $+4.4 \%$ & $-49.2 \%$ \\
\hline
\end{tabular}

The "errors" in table 3 shows that: (1)The errors of yield load and breakage load are less than $10 \%$, except 7C606. Test the steel of 7C606 after the experiment, find the maldistribution of steel strength and whose average is less than the taken value in the theoretical calculation, which is the main reason causing the large error. (2)Concrete strength greater impact on the cracking load and crack deflection. And did not directly measure the crack deflection in the test, but pick it from the inflection of the load-deflection curve, so that they have a larger error and this paper does not carry out in-depth study about it. (3) There is a big gap between the theoretical and experimental result, when using simplified $M-N-\phi$ calculation method to calculate the yield deflection and breakage deflection. The errors are more than $30 \%$ and $60 \%$, respectively. So, the following research concentrate on these 2 parameters.

Calculation Methods. (1) The formula of yield deflection. The formula in 2.4 indicates that $\phi_{y}$ has a decisive role in the calculation. The yield moment of testing beams are known and closer to the calculated results, and the span is known, so a $\phi_{y}$ could be gotten by reverse calculation. The results are shown in Table 4. 
Tab.4 $\left(\phi_{y}, \phi_{y 0}\right)$ Summary

\begin{tabular}{ccc}
\hline $\begin{array}{c}\text { Specimens } \\
\text { number }\end{array}$ & $\begin{array}{c}\text { Inverse } \\
\text { Results } \phi_{y}\end{array}$ & $\begin{array}{c}\text { Calculation } \\
\text { results } \phi_{y 0}\end{array}$ \\
\hline $4 \mathrm{C} 406$ & $1.14311 \mathrm{E}-05$ & $1.01331 \mathrm{E}-05$ \\
$6 \mathrm{C} 406$ & $1.68309 \mathrm{E}-05$ & $1.43689 \mathrm{E}-05$ \\
$7 \mathrm{C} 406$ & $2.66584 \mathrm{E}-05$ & $1.84468 \mathrm{E}-05$ \\
$7 \mathrm{C} 410$ & $2.87658 \mathrm{E}-05$ & $1.93811 \mathrm{E}-05$ \\
$7 \mathrm{C} 606$ & $2.66229 \mathrm{E}-05$ & $1.82321 \mathrm{E}-05$ \\
$7 \mathrm{C} 610$ & $2.98833 \mathrm{E}-05$ & $1.90828 \mathrm{E}-05$ \\
\hline
\end{tabular}

Take $\phi_{y 0}$ as X-axis, $\phi_{y}$ for the Y-axis, get the equation: $\phi_{y}=2.01 \phi_{y 0}-0.00001$. Other parameters of the formulas in 2.4 remains unchanged. The comparison of experimental and calculation results of yield deflection before and after the correction of the formula are shown in figure 8 and 9. The distribution of points in the figure shows that the results of simplified $M-N-\phi$ calculation method are generally smaller than the experimental value, and the results of the corrected formula are more consistent with the experimental results.

(2) Using the same way of (1) to get $\phi_{u}$ by reverse calculation, and the results are shown in Table 5.

Take $\phi_{u 0}$ as $\mathrm{X}$-axis, $\phi_{u}$ for the $\mathrm{Y}$-axis, get the equation: $\phi_{u}=1.57 \phi_{y 0}+0.0002$. Other parameters of the formulas in 2.6 remains unchanged. The comparison of experimental and calculation results of

Tab.5 $\left(\phi_{u}, \phi_{u 0}\right)$ Summary

\begin{tabular}{ccc}
\hline $\begin{array}{c}\text { Specimens } \\
\text { number }\end{array}$ & $\begin{array}{c}\text { Inverse } \\
\text { Results } \phi_{u}\end{array}$ & $\begin{array}{c}\text { Calculation } \\
\text { results } \phi_{u 0}\end{array}$ \\
\hline $4 \mathrm{C} 406$ & 0.000146256 & $7.56568 \mathrm{E}-05$ \\
$6 \mathrm{C} 406$ & 0.000110529 & $5.91318 \mathrm{E}-05$ \\
$7 \mathrm{C} 406$ & 0.000115673 & $4.38277 \mathrm{E}-05$ \\
$7 \mathrm{C} 410$ & $6.24559 \mathrm{E}-05$ & $2.59657 \mathrm{E}-05$ \\
$7 \mathrm{C} 606$ & 0.000122528 & $6.43182 \mathrm{E}-05$ \\
$7 \mathrm{C} 610$ & $7.51039 \mathrm{E}-05$ & $3.81053 \mathrm{E}-05$ \\
\hline
\end{tabular}

breakage deflection before and after the correction of the formula are shown in figure 10 and 11 . The distribution of points in the figure shows that the results of simplified $M-N-\phi$ calculation method are also generally smaller than the experimental value, and the results of the corrected formula are more in line with the experimental results.

\section{Conclusions}

(1) The experimental results indicate that under the conditions of the same reinforcement ratio, the high-strength steel has very notable significance to improve the bearing capacity of the beam. The bearing capacity of HTB600 beams are about 40\% higher than the HRB400 beams; the bearing capacity of HTB700 beams are about $60 \%$ higher than the HRB400 beams. The yield deflection and breakage load of the beam are also gradually increased with the continuous enhancement of the steel strength.

(2) The experiment shows that the effect of high-strength steel to the cracking load is not obvious. Yield load, yield deflection, cracking load and cracking load are gradually increased with the increase of the steel strength and reinforcement ratio. When using the same kind of rebar, the yield deflection increased with the increase of the reinforcement ratio, but the breakage deflection decreased.

(3) Calculate the periodical value of load and deflection of the concrete beams according to the code and simplified $M-N-\phi$ calculation method. After the comparative analysis of the test results, combined with the characteristics of high strength steel, amend the calculation formula for the 
deflection of yield and breakage of high strength reinforced concrete beam. And the calculation result coming from the amended formula are in good agreement with the experimental results.

\section{References}

[1] XuDingyu. Anti-breaking mechanism and design parameters research on high-speed railway tunnel engineering through the Wenchuan seismic fracture zone. Beijing: Beijing Jiaotong University, (2015)

[2] YuHui, LiuMin and FangWanqing. Application and Computational Analysis of Reactor Pressure Vessel with Reinforced Concrete of High Steel Ratio. Building Science, Vol.31, No.7 (2015)

[3] GB50010-2010. Code for design of concrete structures. Beijing: China Architecture \& Building Press(2011)

[4] ZhouJianmin,WangTiao. Research on Crack-width of Concrete Beam Reinforced with High-strength Bars. Journal of Tongji University(Natural Science), Vol.10, No.7 (2011)

[5] ZhouJianmin, ChenShuo. alculation Methods of Short. term Deformationof Concrete Beams with High Strength Steel Bars. Journal of Tongji University(Natural Science),Vol.41,No.4(2013)

[6] HuangWei, DingQiongdi, YangLei. Contrast Analysis of Shear Perfonnance of High-strengm RC Beams. Journal of Anhui university of Technology(Natural Science),Vol.29,No.1(2012)

[7] GeWenjie, ZhangJiwen. Experimental and Parametric Analysis of the Flexural Behavior of HRBF RC Beams. Journal of Civil, Architectural \& Enviromental Engineeering,Vol.35,No.2(2013)

[8] GB/T50152-2012.Standard for test method of concrete structures. Beijing: China Architecture \& Building Press(2013)

[9] ACI 318M-05 Building code requirements for structural concrete and commentary [S]. USA: America Concrete Institute (2005)

[10] GuXianglin. Basic Concepts of Concrete Structures. Shanghai: Tongji University Press (2011)

[11] GuoZhenhai, ShiXudong. Principle and analysis of reinforced concrete Structures. Beijing: Tsinghua University Press (2003)

[12] LONG Yu-qiu,BAO Shi-hua.Structural mechanics. Beijing: Higher Education Press (2006)

[13] HE Zheng, OU Jin-ping. Nonlinear Analysis of Reinforced Concrete Structures[M]. Harbin: Harbin Institute of Technology press (2006) 